\title{
Nutritional treatment improves the effectiveness of anti-cancer therapy
}

\author{
Michał Jankowski
}

Cancer disease is a growing health problem in today's world.

Malnutrition frequently occurs in cancer patients and is associated with their higher mortality rates.

Nutritional interventions are recommended whenever clinically required and at every stage of oncological therapy. This allows prevention or treatment of cancer therapy-related complications thereby improving the effectiveness of such therapy, reducing cost, improving the quality of life, and prolonging the survival of some patients. From an overall perspective, adequate nutrition is necessary to ensure the most favourable outcomes of oncological therapy.

NOWOTWORY J Oncol 2017; 67, 5: 313-315

Key words: anticancer therapy, nutritional treatment/therapy

\section{Introduction}

Cancer is a growing problem in today's world with more than 14 million sufferers estimated for 2017 [1]. The highly developed countries of the West bear the highest risk, nevertheless anti-cancer treatment in these countries is the most effective [2]. Such cures mostly depend on applying appropriate local treatment methods: surgery and radiotherapy, supplemented by systemic treatment. Quoting Professor Tadeusz Koszarowski,'cancer treatment forms part of an integrated therapy including surgery and coordinated in its broadest sense with radiotherapy, chemotherapy and endocrine-therapy'. Nowadays, the role of nutritional intervention is also a prerequisite.

\section{Cancer patients malnutrition}

Malnutrition in cancer patients is multifactorial, arising both from insufficient nutrients supplied as well their increased loss because of the increased demand during cancer development and the presence of other accompanying diseases. Malnutrition is associated with elevated mortality rates in cancer patients; as is likewise the case with other diseases, for example in cardiovascular disease [3].
An inadequate supply of nutrients is a very common occurrence in oncological patients and is accompanied by weight loss; this often being quite appreciable. In clinical practice, weight loss will occur anyway when patients cannot orally consume food for more than a week or when energy needs are met in less than $60 \%$ of required levels for more than 1-2 weeks $[4,5]$.

A study by Martin et al on 11,000 patients with advanced malignancy confirmed that weight loss linked to a low BMI is an independent factor for overall survival (OS) [6]. Current recommendations define a nutrition high risk group (Tab. I), where the risk of complications associated with malnutrition is greatest $[7,8]$.

\section{Recommendations}

At present, a combination of therapeutic methods used affords the greatest opportunities, after appropriate qualification for treatment, with the simultaneous use of supporting therapy. In Poland, recommendations for nutritional treatment in oncology were published in 2015 [9]. Such nutritional intervention was recommended whenever clinically indicated (Tab. II) and at any step of oncological treatment.

Chair of Surgical Oncology, Ludwik Rydygier Collegium Medicum in Bydgoszcz,

Nicolaus Copernicus University in Toruń, Poland

Department of Surgical Oncology, Oncology Center — Prof. Franciszek Lukaszczyk Memorial Hospital, Bydgoszcz, Poland 
Table I. Severe nutritional risk — ESPEN Guidelines [7]

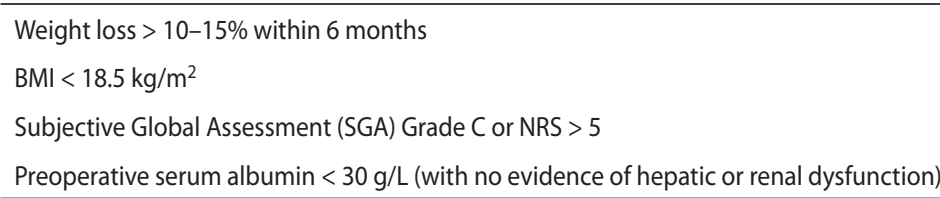

Table II. Indications for nutritional intervention, Polish recommendations [9]

Inability of adopting an oral diet for more than 7 days

Current or threatening malnutrition $\left(\mathrm{BMI}<\mathbf{1 8 . 5} \mathrm{kg} / \mathrm{m}^{2}\right)$

Unintentional weight loss $>10-15 \%$ in 6 months before treatment

Inability to maintain a daily food intake $>60 \%$ of the recommended standard for more than 10 days

Stage $\mathbf{B}$ and $\mathbf{C}$ in the SGA scale or a score of $\geq \mathbf{3}$ points in the NRS 2002 screening method

\section{Perioperative feeding}

The adverse impact of malnutrition on deteriorating outcomes following surgery has been well recognized in the literature since the 1970 s and is still present today.

Initial reporting of nutritional intervention based on parenteral nutrition demonstrated, among other things, a reduced complication risk, especially sepsis, shortened hospital stays $[10,11]$, and even reduced mortality for surgical patients [12]. In view of the complications associated with supplying nutrients by this route, recommendations published in 2006 and in 2009 by the European Society for Clinical Nutrition and Metabolism (ESPEN) advise an enteral route [13], and if proving unfeasible, then a parenteral means be used (Fig. 1) [14, 15].

In those patients without malnutrition symptoms, any preoperative starvation should be avoided, as being part of perioperative care, and $60 \%$ of the body's energy requirements should be met as soon as possible accord- ing to the principles of ERAS (Enhanced Recovery After Surgery) [7-9].

\section{Nutrition therapy in systemic treatment}

During systemic treatment there are no indications for routinely using enteral or parenteral nutrition. An indication for intervention would be weight loss or its likely risk, especially in cases of advanced cancer disease [8]. However, nutritional therapy has a significant role in patients undergoing bone marrow transplantation, where high-dose myeloablative chemotherapy is used. Almost all patients reach enteropathy, and introducing nutritional therapy early on allows the patient to complete their treatment and influence outcomes [16].

\section{Nutritional treatment in radiotherapy}

Weight loss is very common upon using radiotherapy, particularly when combined with chemotherapy. This problem

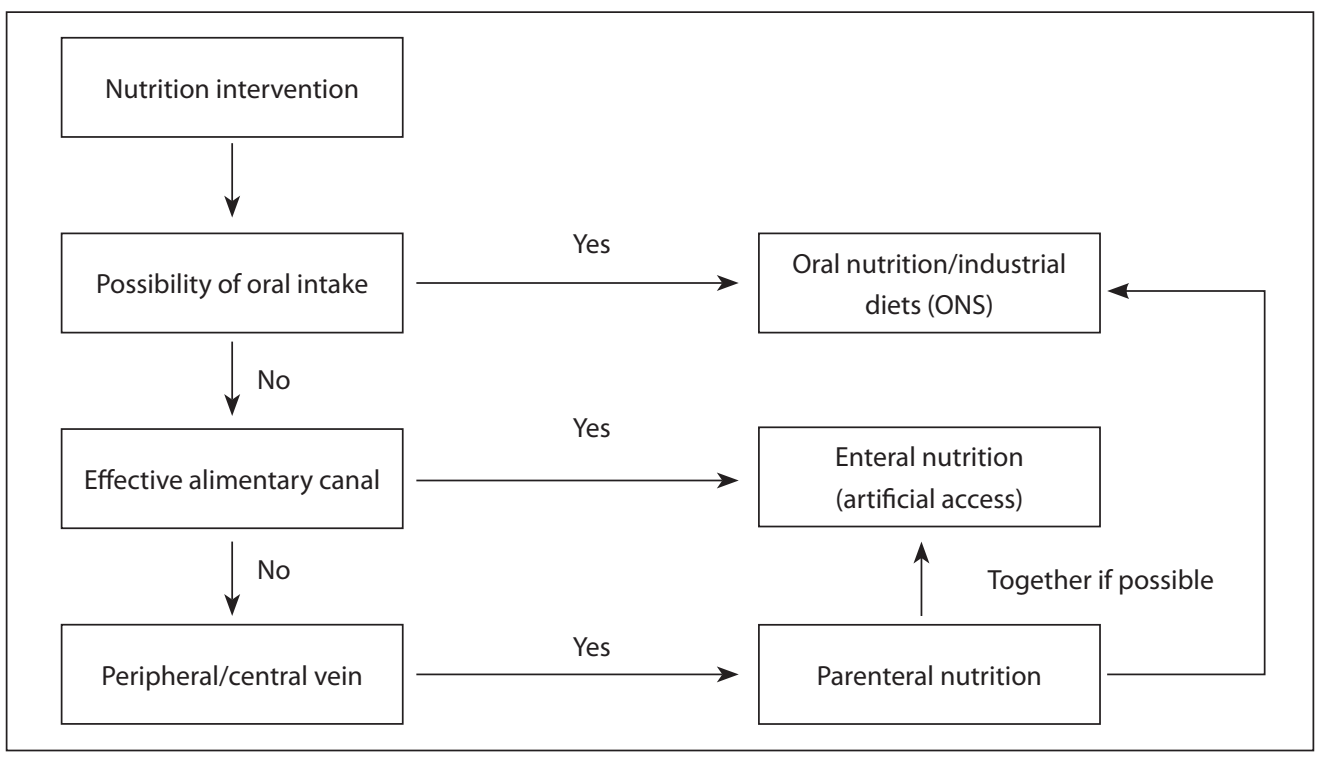

Figure 1. Methods of delivering nutrition interventions [15] 
very often concerns patients undergoing radio-chemotherapy due to head and neck cancers where nutritional intervention beneficially effects nutritional status and the quality of life [17]. Nutrition therapy, often in the form of parenteral nutrition, may also be an indispensable element in cases of irradiated intestinal inflammation, even lasting for many years [18].

\section{Cachexia, sarcopenia}

Cachexia is a multifactorial syndrome, characterized by significant losses in weight as well as in adipose and muscle tissues, and a generalized inflammatory reaction. A definition popularized by Fearon also includes precachexia with only a little weight loss and a developed cachexia, which leads to death in less than 3 months [19]. Cachexia is particularly common in oncological patients and can be accompanied by locally or locoregionally advanced cancers [20]. Its presence shortens survival, as is also in the case for advanced cancer [21].

Sarcopenia indicates among others a muscle mass decline most commonly associated with age, which occurs secondary in patients with malignant tumors. Its presence has an adverse prognostic significance and increases the risk of postoperative complications, as well as the toxicity of chemotherapy and on mortality [22].

\section{Oncological patients after treatment}

Nutritional support in many cases is relevant to patients who have completed radical oncological treatment. It is often essential in those with complications such as: short bowel syndrome, conditions after esophageal or stomach resection. Cured patients are significantly more likely to suffer from other medical conditions, thereby leading to poor health and an impaired quality of life linked also to health [23].

\section{Summarizing}

In conclusion, weight loss, muscle mass reduction are adverse prognostic factors in patients with cancer. Nutritional intervention allows any complications to be prevented or treated during cancer therapy, thereby improving its effectiveness, reducing cost, improving the quality of life, and prolonging the survival of some patients. As a general aim it is necessary to obtain the best outcomes for any oncological treatment.

Conflict of interest: none declared

\section{Michał Jankowski, MD, PhD}

Nicolaus Copernicus University Collegium Medicum

Oncology Centre - Prof. Franciszek Łukaszczyk Memorial Hospital Chair of Surgical Oncology

ul. Romanowskiej 2

85-796 Bydgoszcz, Poland

e-mail:michaljankowski@post.pl
Based on the presentation at the V Annual Conference of the Nowotwory Journal of Oncology, 'Oncological Debates, held in Warszawa, 7-8th April 2017

\section{References}

1. Torre LA, Bray F, Siegel RL et al. Global cancer statistics, 2012. CA Cancer J Clin 2015; 65: 87-108.

2. Vineis P, Wild CP. Global cancer patterns: causes and prevention. Lancet 2014; 383: 549-557.

3. Zheng W, McLerran DF, Rolland B et al. Association between body-mass index and risk of death in more than 1 million Asians. N Engl J Med 2011; 364: 719-729.

4. Arends J, Bodoky G, Bozzetti F et al. ESPEN guidelines on enteral nutrition: non-surgical oncology. Clin Nutr 2006; 25: 245-259.

5. Bozzetti F, Arends J, Lundholm K et al. DGEM (German Society for Nutritional Medicine), ESPEN (European Society for Parenteral and Enteral Nutrition). ESPEN guidelines on parenteral nutrition: non-surgical oncology. Clin Nutr 2009; 28: 445-454.

6. Martin L, Senesse P, Gioulbasanis I et al. Diagnostic criteria for the classification of cancer-associated weight loss. J Clin Oncol 2015; 33: 90-99.

7. Weimann A, Braga M, Carli F et al. ESPEN guideline: Clinical nutrition in surgery. Clin Nutr 2017; 36: 623-650.

8. Arends J, Bachmann P, Baracos $V$ et al. ESPEN guidelines on nutrition in cancer patients. Clin Nutr 2017; 36: 11-48.

9. Kłęk S, Jankowski M, Kruszewski WJ et al. Clinical nutrition in oncology: Polish recommendations. Nowotwory J Oncol 2015; 65: 320-337.

10. Klein S, Simes J, Blackburn GL. Total parenteral nutrition and cancer clinical trials. Cancer 1986; 58: 1378-1386.

11. Veterans Affairs Total Parenteral Nutrition Cooperative Study Group. Perioperative total parenteral nutrition in surgical patients. N Engl J Med 1991; 325: 525-532.

12. Smale BF, Mullen JL, Buzby GP et al. The efficacy of nutritional assessment and support in cancer surgery. Cancer 1981; 47: 2375-2381.

13. Weimann A, Braga M, Harsanyi L et al. ESPEN Guidelines on Enteral Nutrition: Surgery including organ transplantation. Clin Nutr 2006; 25: 224-244.

14. Braga $M$, Ljungqvist $O$, Soeters $P$ et al. ESPEN guidelines on parenteral nutrition: surgery. Clin Nutr 2009; 28: 378-386.

15. Jankowski M, Kapała A, Las-Jankowska M. Obecne zalecenia leczenia żywieniowego $u$ chorych na nowotwory złośliwe [The current recommendations on nutritional therapy in patients with maligancies]. Medycyna Praktyczna. Onkologia 2016; 65.

16. Fuji S, Mori T, Khattry N. Severe weight loss in 3 months after allogeneic hematopoietic SCT was associated with an increased risk of subsequent non-relapse mortality. Bone Marrow Transplant 2015; 50: 100-105.

17. Langius JA, Zandbergen MC, Eerenstein SE et al. Effect of nutritional interventions on nutritional status, quality of life and mortality in patients with head and neck cancer receiving (chemo)radiotherapy: a systematic review. Clin Nutr 2013; 32: 671-678.

18. Hauer-Jensen M, Wang J, Denham JW. Bowel injury: current and evolving management strategies. Semin Radiat Oncol 2003; 13: 357-371.

19. Fearon K, Strasser F, Anker SD et al. Definition and classification of cancer cachexia: an international consensus. Lancet Oncol 2011; 12: 489-495.

20. Muscaritoli M, Rossi Fanelli F, Molfino A. Perspectives of health care professionals on cancer cachexia: results from three global surveys. Ann Oncol 2016; 27: 2230-2236.

21. Blum D, Stene GB, Solheim TS et al. Validation of the Consensus-Definition for Cancer Cachexia and evaluation of a classification model - a study based on data from an international multicentre project (EPCRC-CSA). Ann Oncol 2014; 25: 1635-1642.

22. Baracos V, Kazemi-Bajestani SM. Clinical outcomes related to muscle mass in humans with cancer and catabolic illnesses. Int J Biochem Cell Biol 2013; 45: 2302-2308

23. Huang IC, Hudson MM, Robison LL et al. Differential impact of symptom prevalence and chronic conditions on quality of life in cancer survivors and non-cancer individuals: a population study. Cancer Epidemiol Biomarkers Prev 2017; 26: 1124-1132. 